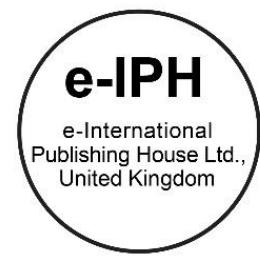

\title{
Effectiveness of Construction Safety Hazards Identification in Virtual Reality Learning Environment
}

\author{
Nurshamshida Md Shamsudin, Faizah Abdul Majid \\ Faculty of Education, \\ University Teknologi MARA Malaysia \\ nurshamshida@uitm.edu.my, faiza404@uitm.edu.my \\ Tel: +60197343322
}

\begin{abstract}
Occupational Safety and Health Act (1994) and efforts taken to ensure the safety of workers in the construction industry. Despite these, accident rates are still alarming. One of the reasons is due to the weak pedagogy, lack of technology integration, and hazardous learning environment that lead towards low learning performance and practicing safety procedures. This study aims to discover the effectiveness of virtual reality simulation learning environment. Results show that there is a significant difference in trainee's achievements in a traditional construction site visit and virtual construction environment. To conclude, virtual reality learning environment offers effective learning platforms for millennials.
\end{abstract}

Keywords: safety hazards; occupational safety and health; virtual reality;

eISSN: 2398-4287 @ 2019. The Authors. Published for AMER ABRA CE-Bs by E-International Publishing House, Ltd., UK. This is an open-access article under the CC BY-NC-ND license (http://creativecommons.org/licenses/by-nc-nd/4.0). Peer-review under responsibility of AMER (Association of Malaysian Environment-Behaviour Researchers), ABRA (Association of Behavioural Researchers on Asians) and cE-Bs (Centre for Environment-Behaviour Studies), Faculty of Architecture, Planning \& Surveying, Universiti Teknologi MARA, Malaysia. DOI: https://doi.org/10.21834/e-bpj.v4i12.1802

\subsection{Introduction}

To address poor OSH performance, researchers and OSH professionals have devoted much effort to understanding and identifying precursors to injury incidents. Among others, human factors have received much recent attention. For example, Hinze (2006) and Haslam, et.al., (2005) found that more than $70 \%$ of injuries involve unsafe worker actions. Tixier, et.al., (2014) explain that such unsafe worker actions are not deliberate safety violations, but are rather outcomes resulting from poor hazard identification. When hazards are not recognized, or when the safety risk is not accurately perceived, workers may not be able to adopt effective OSH measures to prevent injury (Albert, et.al., 2014a; Bahn, 2013; Carter \& Smith, 2006). Many accidents could be prevented and minimized if workers were able to take proper actions by rapidly identifying hazard types and their severity levels. Evia \& Ph (2011) emphasized the importance of training programs in reducing the injuries number (Chen \& Kleiner, 2014).

\subsection{Background of Study}

There were many efforts has been taken by $\mathrm{NIOSH}$ and $\mathrm{CIDB}$ to adapt a wide variety of training programs to improve hazard identification. However, the prevalent use of ineffective, unengaging, and poorly designed training programs significantly impedes training efforts (Wilkins, 2011). In fact, Li, et.al., (2012) argue that a positive correlation does not exist between traditional safety training and safety performance. Not surprisingly, workers lack essential safety knowledge despite having received substantial safety training (Haslam, et.al., 2005). For effective training, employers and organizations must adopt training practices that will yield maximum benefits. In attempts to improve OSH training and education, virtual reality (VR) technologies have been applied and proved beneficial in various disciplines (Sampaio, et.al., al., 2010). Conversely, very few studies have focused on the application of these technologies to OSH hazard training using the virtual reality platform. Current research findings show that the implementation of the VR training approach is

eISSN: 2398-4287 @ 2019. The Authors. Published for AMER ABRA CE-Bs by E-International Publishing House, Ltd., UK. This is an open-access article under the CC BY-NC-ND license (http://creativecommons.org/licenses/by-nc-nd/4.0). Peer-review under responsibility of AMER (Association of Malaysian Environment-Behaviour Researchers), ABRA (Association of Behavioural Researchers on Asians) and cE-Bs (Centre for Environment-Behaviour Studies), Faculty of Architecture, Planning \& Surveying, Universiti Teknologi MARA, Malaysia.

DOI: https://doi.org/10.21834/e-bpj.v4i12.1802 
promising not only in reducing cost; however it is promoting efficient, effective training effort but also able to aim towards accurate and precise training objectives.

\subsection{Literature Review}

\subsection{Effectiveness of OSH training}

Training Transfer, although practical training can improve safety knowledge, it is not sufficient by itself to yield expected benefits. This is because workers often fail to apply learned concepts and skills once they return to work (Blume, et.al., 2010). In other words, knowledge transfer is not equivalent to training transfer or the application of learned concepts in practice. In fact, in most cases, only $10-15 \%$ of training expenditure translates into noticeable improvements in work practices and performance; the rest generally reduces to wasted resources (Cromwell \& Kolb, 2004). Evidence for the failure of training transfer is abundant within the construction industry. A plausible explanation for this disconnect between safety knowledge gain and objective safety outcomes is the failure of training transfer. Given that only a small fraction of training expenditure translates into tangible safety benefits ( 10-15\%), even a minor increase in training transfer (e.g., by 30-50\%) can dramatically enhance safety performance. Therefore, identifying and implementing training transfer elements that facilitate the transfer of training is particularly essential for the construction industry.

\subsection{Transfer of Training}

To increase the effectiveness of training, it is best to consider the level of engagement during training and how much training can be transferred. In the context of Occupational Safety and Health training transfer should happen at the workplace to reduce the rate of injuries and fatalities and to increase safety performance. According to Holton (2005), one cause of failure to transfer is that training design rarely provides for the transfer of learning. That is, cognitive learning may well occur, but program participants may not have an opportunity to practice the training in a job context or may not be taught how to apply their knowledge on the job. So the training itself can have a direct influence on the transfer of training.

\section{Training Design of Virtual Reality and Performance}

The purpose of the study by Joo et.al., (2011) the study described by Rosen (2009) is among the first of its kind to investigate systematically the effect of learning with integrated animations on the transfer of knowledge and on motivation to learn science and technology. The results showed a significant effect of the narrative and immersion phase, and significant interactions between narrative and immersion,. This study to formulate of the formation of hypotheses $\mathrm{H} 1 \mathrm{a}$ and $\mathrm{H} 1 \mathrm{~b}$.

Hypothesis 1a: There is a positive relationship between HI-VRS features and learning performance. Hypothesis $1 \mathrm{~b}$ : There is a positive relationship between $\mathrm{HI}-\mathrm{VRS}$ features and $\mathrm{OSH}$ performance.

Involvement and immersion in learning in a study by Hamari et.al., (2016) focus game-based learning environment. Riva et al., (2007) conduct a study to analyze the advantages of using VR as an effective medium. In general, this study wants to confirm that there is a relationship between presence and emotion. The results of the study highlight that the results confirm the effectiveness of VR as an effective medium: interactions with "anxious" and "relaxed" virtual environments produce anxiety and relaxation. The results of this study emphasize that in the use of virtual reality, the importance of interactive elements in the development of virtual reality simulations. Hence $\mathrm{H} 2 \mathrm{~A}$ and $\mathrm{H} 2 \mathrm{~B}$ is formulated,

Hypotheses 2a: There is a positive relationship between HI-VRS Immersion and learning performance.

Hypothesis $2 \mathrm{~b}$ : There is a positive relationship between HI-VRS Immersion and OSH performance.

Chi et.al., (2010) The purpose of this study is to design and develop the Interactive Physical Learning Environment, the PILE system, with the realization of virtual reality simulations. This system includes learning activities comprising six levels, and each stage is designed with different devices. Among the critical findings, the interactions that exist within the virtual reality are the essential element that causes a significant impact on effective learning outcomes. VR applications increase usage in psychological research. Wilson et al, (2015) focus of the study is focused on the field of visual perception, where both VR's advantages and challenges are crucial. Visualization is to realize the interaction with the user to improve the development of virtual reality applications. Therefore, this study formulates on the hypotheses of $\mathrm{H} 3 \mathrm{a}$ and $\mathrm{H} 3 \mathrm{~b}$ of this study.

Hypotheses 3a: There is a positive relationship between HI-VRS Interaction and learning performance.

Hypothesis $3 b$ : There is a positive relationship between HI-VRS Interaction and OSH performance.

\section{Training Using Virtual Reality and Reaction}

Hussein \& Nätterdal (2015) study on astronomy learning using virtual reality among 20 students and five educators through interviews. By analyzing the results, it is have found that VR is especially useful in subjects where an interactive environment is needed. Chaisanit (2017) examine the satisfaction of learners towards the interactive simulation and virtual reality museum: the tradition of Chonburi province. The sampling group of this study was 40 learners. The satisfaction of interactive and content on the interactive simulation and virtual is considered moderate. Lee et. al., (2009) to compare the effectiveness of a desktop virtual reality-based learning environment with a conventional classroom learning practice. The learning effectiveness was measured through academic performance, perceived learning, and satisfaction. There was a significant difference in academic performance, perceived learning, and satisfaction between the 
two groups. It was concluded that the virtual desktop reality instructional program positively affects the students' academic achievement and their perceived learning quality and satisfaction.

\subsection{Method}

This stage of study involves a quantitative approach. The objective of this stage is to gain the effectiveness of training using developed training simulations prototype, HI-VRS. The evaluation phase adapted Kirkpatrick (2006) that involve three levels of evaluation are followed intimately involved three levels which are;

Evaluation Level 2: To evaluate trainee learning performance on the application of HI-VRS during hazard identification at a construction site in SSS training. (Knowledge and skills changes).

Evaluation Level 3: To evaluate trainee safety performance at the workplace on the application of HI-VRS after hazard identification training. (Behaviour changes).

\subsection{Instruments}

For evaluation of the effectiveness of HI-VRS training simulations prototype towards trainee ability on hazard, identifications include HIVRS. The questionnaire was developed based on a few adaptations (Warmer \& Singer, 2005). There are 32 items developed and divided into themes. The items were examined and validated by two experts in virtual reality and instructional technology.

\subsection{Data Analysis using PLS-SEM for Quantitative (Evaluation)}

PLS-SEMM is choosing to provide model latent psychometrics variables. The PLS-SEM is for model and hypotheses testing because it can be used for non-parametric and method for the prediction-oriented study. The model-testing was conducted via the componentbased Partial Least Squares Structural Equation Modeling (PLS-SEM) in SmartPLS 3.0 M3 (Ringle et.al., 2005). PLS estimation is nonparametric, and no restrictive assumptions about the distributions of the data. Secondly, PLS-SEM is a more suitable method for prediction-oriented studies (such as the present study). In PLS-SEM, two types of measurement were conducted on i) measurement model and ii) structural model

\section{Measurement Model}

The evaluation of the Measurement model involves on validity and reliability. Involve four assessments on construct validity, convergent validity, discriminant validity, and reliability analysis.

\section{Structural Model}

The structural model assessed through the bootstrapping procedure using 5000 samples. This procedure conducted as suggested by Henseler, et.al., (2009) Hair, et.al., (2011) Henseler, et.al., (2016) is to examine the path coefficient significance.

\subsection{Results}

\section{Data Preparation for Analysis using PLS-SEM}

Before data analysis can be conducted, the collected data was examined thoroughly through its accuracy of data entry, outliers, and data distribution. Data screening was carried with the recognizing of missing data, outliers, normality, and linearity.

Table 1: Collinearity Statistics (VIF)

\begin{tabular}{lll}
\hline & Learning & Safety \\
Engagement & 1.308 & 1.452 \\
HI-VRS & 1.395 & 1.511 \\
Immersion & 1.080 & 1.100 \\
Learning & & 1.443 \\
Safety & & \\
\hline
\end{tabular}

\section{Measurement Model}

To evaluate the measurement model, it is involved two criteria, which are validity and reliability. For the assessment of reflective measurement items Hair (2017) recommends applying the construct validity, convergent validity, and discriminant validity. The measurement model then proceeds with reliability analysis.

\section{a. Construct Validity}

According to Sekaran \& Bougie (2010), construct validity determine that it refers to the degree to the results obtained from the use of measure that could fit the theories upon which the test is developed. Hair (2014) stated that it is essential that the indicator loading is 0.7; however, there are also could be used between 0.4-0.7. Therefore, the cut-off for factor loadings in the present study is 0.4 . Manifest 
variables with outer loading 0.7 or higher are considered highly satisfactory While loading value of 0.5 is regarded as acceptable, the manifest variables with loading value of less than 0.5 should be dropped Hulland (1999) argued that 0.4 should be the acceptable loading value where Henseler, et.al.,(2014) suggested that manifest variable with loading values between 0.4 and 0.7 should be reviewed before elimination. If the elimination of these indicators increases the composite reliability, then discard or otherwise maintain the factors. Even though for this study, the cut-off value taken for outer loading is 0.5 , an iterative process is adopted for the elimination of the manifest variables by considering Henseler, et.al., (2014) suggestion.

\section{b. Convergent Validity}

The convergent validity of the measurement is usually ascertained by examining the loadings, average variance extracted (AVE), and the composite reliability (Gholami, et.al., 2013). Researchers are recommended to use factor loadings, composite reliability (CR), and average variance extracted (AVE) for the assessment of convergent validity (Hair, et.al., 2012).

\section{c. Discriminant Validity}

There has been recent criticism that the Fornell-Larcker (1981) criterion does not reliably detect the lack of discriminant validity in common research situations (Henseler, et.al., 2015). Discriminant validity in this study, as presented in Table 4.61, the diagonal elements denoted that the average variance square root that gained from the latent constructs. To this point, discriminant validity is said to be confirmed if the diagonal elements are higher compared to the other off-diagonal elements in the rows and columns. Hence, this was the case in the correlation matrix, and discriminant validity is confirmed.

Table 2: Fornell-Larcker Criterion

\begin{tabular}{|l|l|l|l|l|l|}
\hline & Engagement & HI-VRS & Immersion & Learning & Safety \\
\hline Engagement & 0.790 & & & & \\
\hline HI-VRS & 0.485 & 0.811 & & & \\
\hline Immersion & -0.110 & -0.271 & 0.754 & & \\
\hline Learning & 0.466 & 0.469 & -0.231 & 0.977 & \\
\hline Safety & 0.362 & 0.725 & -0.089 & 0.439 & 0.789 \\
\hline
\end{tabular}

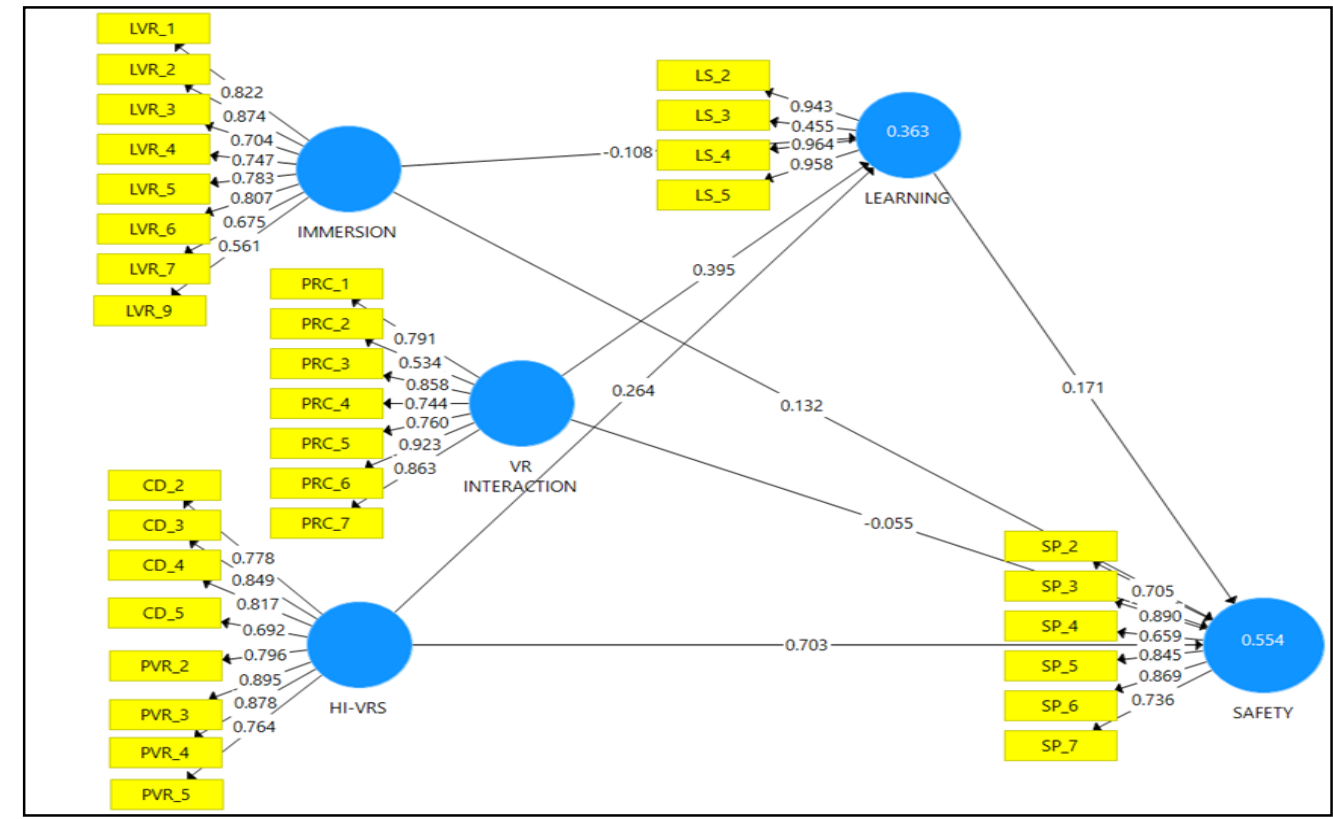

Figure 1: Measurement Model

\section{Reliability Analysis}

Composite reliability is applied for the assessment of inter-items consistency, as stated by Hair et.al., (2014). The recommended CR values need to exceed more than 0.7 Hair (2011). The CR value for each construct is as below. It is evident from the values that the recommended value is exceeded, as shown in Table 4.62.

Table 3: Composite Reliabilities of Constructs

\begin{tabular}{lcl} 
& Table 3: Composite Reliabilities of Constructs \\
\hline Construct & Items & Composite Reliability (CR) \\
Hi-VRS & 8 & 0.939 \\
IMMERSION & 9 & 0.911 \\
\hline
\end{tabular}




\begin{tabular}{lll}
\hline INTERACTION & 7 & 0.92 \\
LEARNING PERFORMANCE & 4 & 0.913 \\
OSH PERFORMANCE & 6 & 0.907 \\
\hline
\end{tabular}

\section{Structural Model}

The structural model was assessed using a bootstrapping procedure with 5000 bootstrap samples and 316 cases. The first step involves the assessment of the significance of the direct relationship of the structural model, and the significance of the structural model through mediator effects was also assessed.

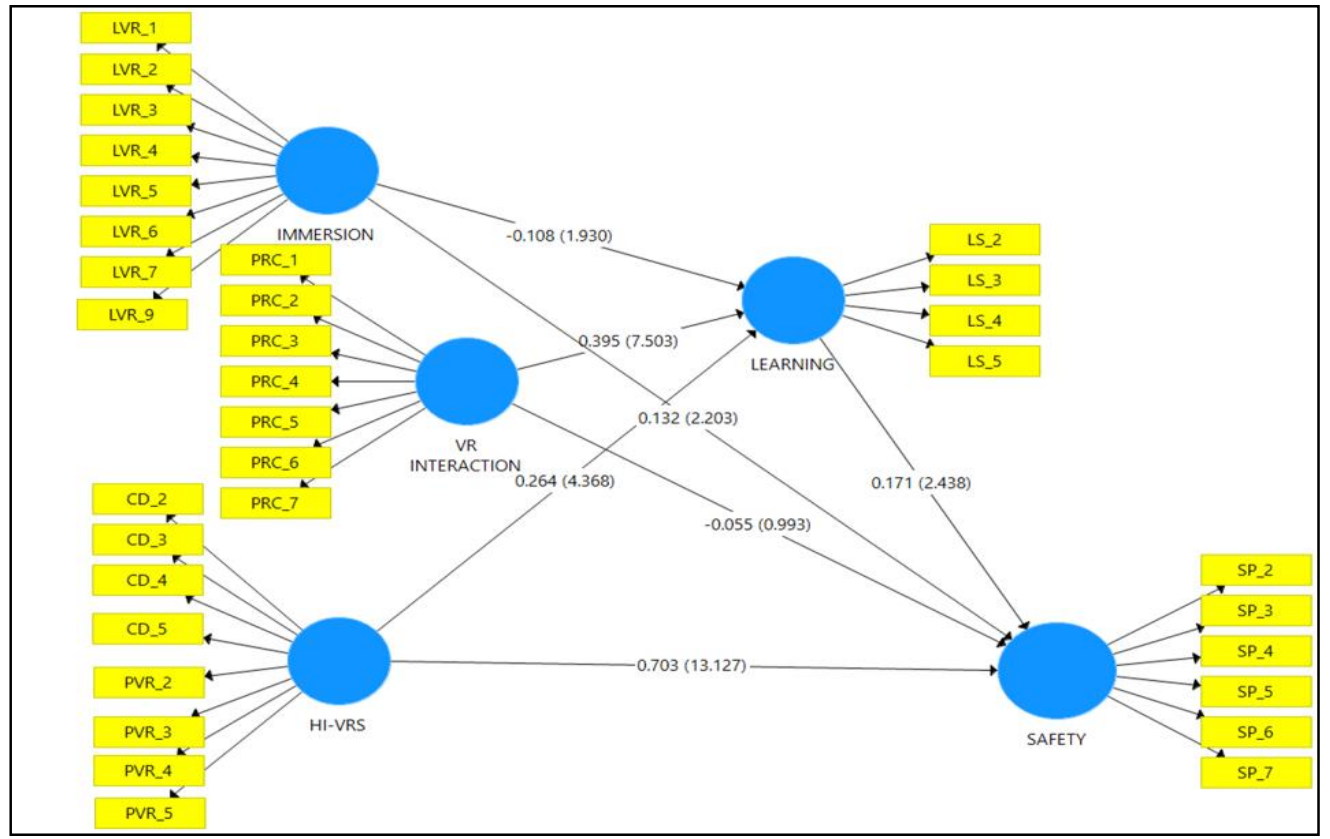

Figure 2: Structural Model

\section{Assessment of Significance of the Structural Model (Direct Relationship)}

The assessment will involve three main designs of HI-VRS; features, immersion, and interaction. For virtual training features, the structural model estimates, including the direct relationship. The first proposed Hypotheses 1a: There is a positive relationship between HI-VRS features and learning performance, a significant relationship between the two variables at $(\beta=0.264, t=4.368 p<p<0.01)$, indicating support for Hypothesis1a.Hypotheses $1 \mathrm{~b}$ proposed that HI-VRS features positively related to OSH performance shows a significant relationship between HI-VRS Features and OSH performance at $(\beta=0.703, t=13.127 p<p<0.01)$ indicating support for this hypotheses.

For virtual immersion, moving on to Hypotheses 2a, it is predicted a significant relationship between HI-VRS immersion and learning performance; however, the result showed a negative relationship and no significant relationship between the two at $(\beta=-0.108, t=1.93$, $\mathrm{p}<0.01$ ), indicating that this hypothesis is rejected. Hypotheses $2 \mathrm{~b}$ proposed to show that there is a positive relationship between $\mathrm{HI}-$ VRS Immersion and $\mathrm{OSH}$ performance. The result shows that there is a significant relationship between immersion and OSH performance. $(\beta=0.132, t=2.203, p<0.01)$.

For virtual interaction, Hypotheses $3 a \mathrm{p}$

roposed that there is a positive relationship between HI-VRS Interaction and learning performance. Results show a significant relationship exists between these two variables at $(\beta=0395, t=7.503, p<0.01)$; therefore, this hypothesis is accepted. While Hypotheses $3 \mathrm{~b}$; this is to relate between HI-VRS Interaction and OSH performance; however, results show that a negative relationship and no relationship between the two variables at $(\beta=-0.055, t=0.993, p>0.05)$. Hypotheses 6 used to relate Learning and OSH performance, and results show that $(\beta=0.171, t=2.438, p<0.01)$ indicating that this hypothesis is accepted.

\subsection{Discussions}

In this study investigated the impact of interaction and immersion and VR features on learning in virtual environments. The study suggests that educational virtual reality can effectively engage students in a learning activity, as demonstrated by heightening levels of engagement through interaction, and immersion VR features and that this may be activated by increasing levels of interactions. The results specifically showed that interaction in the virtual environment had a positive effect on learning. Immersion, in this study, on the other hand, did not have a significant effect. 


\section{i. Virtual Features}

This study investigated the impact of VR features on learning in virtual environments. The present study suggests that virtual reality can effectively engage students in a learning activity, as demonstrated by heightening levels of engagement through interaction, and immersion VR features and that this may be activated by increasing levels of interactions. The results specifically showed that interaction in the virtual environment had a positive effect on learning. Immersion, in this study, on the other hand, did not have a significant effect. This finding is consistent with those by Riva (2007) and Chin (2010), which found that there is an influence of Virtual features and learning and OSH performance.

\section{ii. Virtual Reality Immersion}

Liebert (2001) stated that immersion is engaged through a mediated environment. Simulation promotes learning engagement.( Hence, learning skills that involve procedural skills Darragh, et.al., (2016) will have a great advantage. Virtual reality simulation has its advantage by having the immersion in the simulation. Immersions encourage engagement that could influence on the improvements of procedural skills and knowledge. Darragh et.al., (2016) recommend that immersion could have a great impact on the trainees on performing the job after training has been attended. Liebert (2001) also argues that immersion is the senses that are engaged in the training environment. However, learning is unable to be mediated by immersion. This happens when immersion can be misinterpreted, especially among firsttime users of virtual reality. Immersion may not be able to encourage active learning; it is focusing on passive learning. Immersion of virtual reality could impact on OSH performance since that HI-VRS provide a complete and optimum learning experience. Immersion is not able to influence learning directly as it serves as a passive simulation. Liebert (2001) stated that feeling immerse could also contribute to VR sickness, especially among the first-time user.

\section{iii. VR Interaction}

The findings of the study show that there is a positive relationship between HI-VRS Interaction and learning performance. VR is a new technology that provides interaction with learning content. This will potentially deepen the learning effect when the learners are actively constructing new knowledge Hanson \& Shelton (2008) through virtual environments. Virtual reality causes the learner to cognitively process the learning material more deeply; learners can acquire knowledge and skills effectively. The ability to provide highly interactive learning experiences is one of the best-valued in virtual reality. Virtual reality interactions offer a learning process; the interaction that occurs in HI-VRS is valuable for hazard identification training substitute for real experience. Huang, et.al., (2010) stated that virtual reality interaction is a crucial factor to affect learning performance. Interactions could provide a highly satisfactory VR environment for users if march-in-place detection devices for mobile phones that can be popularized are developed steadily following the concept of hardware that can accurately detect hand motions through low-priced devices Finding of the study shows that there is no relationship between VR interaction and OSH performance.

\subsection{Conclusions}

This study has a great impact on the implementation of Occupational Safety and Health training and to the construction industry as well. The design of this study conducted gave contributed to the important findings between the current practices and proposed training approach. The utilization of designing and developing mobile virtual reality is also made the study align with the cutting edge of society compared to passive classroom-based training and hazardous site-practical, which are less effective.

\section{References}

Albert, A., Hallowell, M. R., Kleiner, B., Chen, A., \& Golparvar-Fard, M. (2014). Enhancing construction hazard recognition with high-fidelity augmented virtuality. Journal of Construction Engineering and Management, 140(7), 04014024.

Blume, B. D., Ford, J. K., Baldwin, T. T., \& Huang, J. L. (2010). Transfer of training: A meta-analytic review 10-28.Journal of Management, 36(4), $1065-1105$.

Burke, M. J., Salvador, R. O., Smith-Crowe, K., Chan-Serafin, S., Smith, A., \& Sonesh, S. (2011). The dread factor: How hazards and safety training influence learning and performance. Journal of Applied Psychology, 96(1), 46.

Chen, A., Golparvar-Fard, M., \& Kleiner, B. (2014). Saves An augmented virtuality strategy for training construction hazard recognition. In Construction Research Congress 2014: Construction in a Global Network (pp. 2345-2354).

Evia, C. (2010). Localizing and designing computer-based safety training solutions for Hispanic construction workers. Journal of Construction Engineering and Management, 137(6), 452-459.

Gambatese, J. A., Behm, M., \& Hinze, J. W. (2005). Viability of designing for construction worker safety. Journal of construction engineering and management, 131(9), 1029-1036.

Hair, J. F., Sarstedt, M., Ringle, C. M., \& Mena, J. A. (2012). An assessment of the use of partial least squares structural equation modelling in marketing research. Journal of the academy of marketing science, 40(3), 414-433.

Hair, J. F., Ringle, C. M., \& Sarstedt, M. (2011). PLS-SEM: Indeed a silver bullet. Journal of Marketing Theory and Practice, 19(2), $139-152$. 
Hinze, J., Devenport, J. N., \& Giang, G. (2006). Analysis of construction worker injuries that do not result in lost time. Journal of Construction Engineering and Management, 132(3), 321-326.

Haslam, R. A., Hide, S. A., Gibb, A. G., Gyi, D. E., Pavitt, T., Atkinson, S., \& Duff, A. R. (2005). Contributing factors in construction accidents. Applied ergonomics, 36(4), $401-415$

Henseler, J., Ringle, C. M., \& Sinkovics, R. R. (2009). The use of partial least squares path modelling in international marketing. In New challenges to international marketing (pp. 277-319). Emerald Group Publishing Limited.

Henseler, J., Ringle, C. M., \& Sarstedt, M. (2016). Testing measurement invariance of composites using partial least squares. International Marketing Review, 33(3), 405431.

Hair, J. F., Sarstedt, M., Ringle, C. M., \& Mena, J. A. (2012). An assessment of the use of partial least squares structural equation modelling in marketing research. Journal of the academy of marketing science, 40(3), 414-433.

Hair, J. F., Ringle, C. M., \& Sarstedt, M. (2013). Partial least squares structural equation modelling: Rigorous applications, better results and higher acceptance.

Huang, H. M., Rauch, U., \& Liaw, S. S. (2010). Investigating learners' attitudes toward virtual reality learning environments: Based on a constructivist approach. Computers \& Education, 55(3), 1171-1182.

Hussein, M., \& Nätterdal, C. (2015). The benefits of virtual reality in education-A Comparision Study.

Kirkpatrick, D. L. (2006). Seven keys to unlock the four levels of evaluation. Performance Improvement, 45(7), 5-8.

Sarstedt, M., Ringle, C. M., Henseler, J., \& Hair, J. F. (2014). On the emancipation of PLS-SEM: A commentary on Rigdon (2012). Long-range planning, 47(3), 154-160.

Tixier, A. J. P., Hallowell, M. R., Albert, A., van Boven, L., \& Kleiner, B. M. (2014). Psychological antecedents of risk-taking behavior in construction. Journal of Construction Engineering and Management, 140(11), 04014052.

Wikins, J. R. (2011). Construction workers' perceptions of health and safety training programmes. Construction Management and Economics, 29(10), 1017-1026

Wilson, C. J., \& Soranzo, A. (2015). The use of virtual reality in psychology: A case study in visual perception. Computational and mathematical methods in medicine, 2015

Witmer, B. G., Jerome, C. J., \& Singer, M. J. (2005). The factor structure of the presence questionnaire. Presence: Teleoperators \& Virtual Environments, 14(3), $298-312$.

Yang, J. C., Chen, C. H., \& Jeng, M. C. (2010). Integrating video-capture virtual reality technology into a physically interactive learning environment for English learning. Computers \& Education, 55(3), 1346-1356. 